\title{
Pectin Induced Colony Expansion of Soil-Derived Flavobacterium Strains
}

\author{
Judith Kraut-Cohen ${ }^{1 \dagger}$, Orr H. Shapiro ${ }^{2}$, Barak Dror ${ }^{1,3+}$ and Eddie Cytryn ${ }^{1 * \dagger}$ \\ ${ }^{1}$ Institute of Soil, Water and Environmental Sciences, Agricultural Research Organization, Volcani Center, Rishon LeZion, \\ Israel, ${ }^{2}$ Institute of Postharvest and Food Sciences, Agricultural Research Organization, Volcani Center, Rishon LeZion, \\ Israel, ${ }^{3}$ Department of Plant Pathology and Microbiology, The R.H. Smith Faculty of Agriculture, Food and Environment, \\ The Hebrew University of Jerusalem, Rehovot, Israel
}

\section{OPEN ACCESS}

Edited by:

Francisco Dini-Andreote Pennsylvania State University (PSU),

United States

Reviewed by:

Diego Javier Jiménez, University of Los Andes, Colombia,

Colombia

Yongtao Zhu, Minnesota State University, Mankato, United States

*Correspondence: Eddie Cytryn eddie@volcani.agri.gov.il.

${ }^{\dagger}$ Present address: Eddie Cytryn, Judith Kraut-Cohen, and Barak Dror, Institute of Soil, Water and Environmental Sciences, Volcani

Center, Agricultural Research Organization, Rishon LeZion, Israel

Specialty section:

This article was submitted to Microbial Physiology and Metabolism,

a section of the journal

Frontiers in Microbiology

Received: 11 January 2021

Accepted: 22 February 2021

Published: 06 April 2021

Citation:

Kraut-Cohen J, Shapiro OH, Dror $B$ and Cytryn E (2021) Pectin

Induced Colony Expansion

of Soil-Derived Flavobacterium

Strains. Front. Microbiol. 12:651891.

do: 10.3389/fmicb.2021.651891
The genus Flavobacterium is characterized by the capacity to metabolize complex organic compounds and a unique gliding motility mechanism. Flavobacteria are often abundant in root microbiomes of various plants, but the factors contributing to this high abundance are currently unknown. In this study, we evaluated the effect of various plant-associated poly- and mono-saccharides on colony expansion of two Flavobacterium strains. Both strains were able to spread on pectin and other polysaccharides such as microcrystalline cellulose. However, only pectin (but not pectin monomers), a component of plant cell walls, enhanced colony expansion on solid surfaces in a dose- and substrate-dependent manner. On pectin, flavobacteria exhibited bi-phasic motility, with an initial phase of rapid expansion, followed by growth within the colonized area. Proteomic and gene expression analyses revealed significant induction of carbohydrate metabolism related proteins when flavobacteria were grown on pectin, including selected SusC/D, TonB-dependent glycan transport operons. Our results show a positive correlation between colony expansion and the upregulation of proteins involved in sugar uptake, suggesting an unknown linkage between specific operons encoding for glycan uptake and metabolism and flavobacterial expansion. Furthermore, within the context of flavobacterial-plant interactions, they suggest that pectin may facilitate flavobacterial expansion on plant surfaces in addition to serving as an essential carbon source.

Keywords: Flavobacterium, colony expansion, pectin, TonB, glycan

\section{INTRODUCTION}

The complex interactions between plant-associated microorganisms and their hosts (collectively referred to as the "plant holobiont") are crucial for plant health and growth (Berendsen et al., 2012; Bulgarelli et al., 2013; Reinhold-Hurek et al., 2015). Plants modulate their rhizospheres, by exuding various small molecular weight compounds (rhizodeposits) such as sugars, amino acids, and organic acids, by rhizodepositing root cap border cells, and by releasing various monoand polysaccharides in their mucilage (Dennis et al., 2010; Barret et al., 2011; Beauregard et al., 2013; Reinhold-Hurek et al., 2015; Massalha et al., 2017; Sasse et al., 2018). Collectively, these rhizodeposits, create a nutrient rich environment relative to the surrounding bulk soil, which facilitates colonization by soil microorganisms. Root colonizing bacteria can outcompete other soil bacteria by a combination of specific traits collectively coined "rhizosphere competence," which include: motility, resistance to stress, ability to utilize plant-derived organic compounds, 
chemotaxis, and the production of secondary metabolites (Barret et al., 2011). Some earlier studies demonstrated that rootassociated (rhizoplane) bacteria are attracted to the roots by plant-exuded organic acids such as malic, citric or fumaric acid, and various amino acids (Rudrappa et al., 2008; Williams et al., 2008; Oku et al., 2012; Webb et al., 2017; Feng et al., 2019). Many of these sensed chemo-attractants, can also be consumed by the bacteria (Cremer et al., 2019). Although root recruitment and colonization mechanisms of certain plant-growth-promoting rhizobacteria (PGPR) have been identified and characterized (Lugtenberg and Dekkers, 1999; Yan et al., 2008; Pieterse et al., 2014), those responsible for recruitment of the vast majority of rhizoplane bacteria are currently an enigma.

Flavobacterium is a Gram-negative genus of bacteria from the phylum Bacteroidetes known to degrade complex organic compounds in freshwater, marine, and soil environments (Kolton et al., 2013; McBride et al., 2014). It is highly abundant in the rhizoplane of a wide array of plants, in contrast to considerably lower abundance in the rhizosphere and bulk soil (Johansen et al., 2002; Janssen, 2006; Manter et al., 2010; Kolton et al., 2011, 2013; Lundberg et al., 2012; Bodenhausen et al., 2013; Bulgarelli et al., 2015). Several root- and soil-derived flavobacteria were found to antagonize various plant pathogens in different crops (Gunasinghe et al., 2004; Sang and Kim, 2012; Kolton et al., 2014; Xue et al., 2015; Kwak et al., 2018), and recently it was discovered that endophytic Flavobacterium strains play a fundamental role in antagonizing phytopathogenic fungi, through specific secondary metabolites (Carrión et al., 2019). Furthermore, a recent study that applied bacterial network analysis indicated that Flavobacteria are potential drivers of pathogen suppression in root ecosystems (Wei et al., 2019). In addition, selected members of this genus have been characterized as plant growth promoting rhizobacteria (PGPR) of various crops (Hebbar et al., 1991; Alexander and Stewart, 2001; Gunasinghe et al., 2004; Manter et al., 2010; Sang et al., 2011; Sang and Kim, 2012).

Soil flavobacteria have specialized ability to decompose complex plant derived polysaccharides, such as pectin and glucomannan and the ability to secret various carbohydrateactive enzymes via the Bacteroidetes-specific type IX secretion system (T9SS) (McBride et al., 2009; Kolton et al., 2013; Kharade and McBride, 2015; McBride and Nakane, 2015; Lauber et al., 2018). Like other Bacteroidetes, they contain a myriad of genes that encode Polysaccharide Utilization Loci (PULs) that are activated specifically to facilitate glycan capture and sugar uptake (Martens et al., 2009; Jiménez et al., 2015; Foley et al., 2016). These PULs include outer membrane protein transducers involved in polysaccharide utilization, which are part of the TonB family, generally referred to as Starch Utilization System (SUS) proteins. Interestingly, comparative genomics revealed that genomes of soil and root-associated flavobacterial strains are significantly enriched with genes associated with plant polysaccharide degradation relative to aquatic strains from this genus, indicating that physiology of this genus is strongly influenced by its ecology (Kolton et al., 2013).

Most terrestrial Flavobacterium strains possess a unique gliding mechanism that rapidly propels them over solid and semisolid surfaces. The proteins that comprise this gliding system are molecularly intertwined with at least 15 proteins that make up the T9SS, seven of whom are responsible for the secretion of SprB and RemA adhesins which are expressed on the cell surface and involved in gliding (Shrivastava et al., 2013; Johnston et al., 2018). We previously demonstrated that this T9SS-gliding complex is crucial for root colonization by flavobacteria, and this colonization was positively linked to the induction of plant resistance to foliar pathogens (Kolton et al., 2014).

Collectively, the above studies strongly suggest that terrestrial flavobacterial strains have evolved means that enable them to interact with plant roots, and that these interactions are beneficial to plant health. Nonetheless, the specific mechanisms behind this phenomenon are currently unclear. In this study, we assessed the impact of an array of plant cell wall-derived substrates on the motility and growth dynamics of flavobacteria by coupling conventional petri dish assays and live-imaging fluorescent microscopy with proteomic and gene expression analyses. We demonstrate that pectin, a plant cell wallassociated polysaccharide, facilitates bi-phasic proliferation over solid surfaces through induction of specific TonB-associated glycan uptake operons. These results suggests that the link between pectin, motility and carbohydrate metabolism may be fundamental to rhizosphere competence in flavobacteria.

\section{MATERIALS AND METHODS}

\section{Bacterial Strains and Growth Conditions}

Flavobacterial strains targeted in this study included Flavobacterium johnsoniae strain UW101 (ATCC17061), a gliding/secretion impaired $(\Delta g l d J) F$. johnsoniae strain UW101 (Braun and McBride, 2005), Flavobacterium sp. F52, isolated from the roots of a greenhouse pepper (Sela et al., 2012; Kolton et al., 2014), and a gliding/secretion impaired $(\Delta$ gldJ) Flavobacterium sp. F52 strain (Kolton et al., 2014). For live imaging microscopy (see below) the fluorescent strain F. johnsoniae UW101 WT + pAS43 (Flavo GFP) Flavo-ErytRFlavo-CefR, and the gliding/secretion impaired F. johnsoniae UW102-48 ( $\Delta$ gldJ) + pAS43 (Flavo GFP) FlavoErytR Flavo-CefR were used (Mcbride and Baker, 1996; Staroscik et al., 2008). Erythromycin, $100 \mu \mathrm{g} / \mathrm{ml}$ was added to the media of the GFP labeled bacteria.

Flavobacteria strains were grown in CYE medium [Casitone, $10 \mathrm{mg} / \mathrm{ml}$, yeast extract at $5 \mathrm{mg} / \mathrm{ml}$, and $8 \mathrm{mM} \mathrm{MgSO}_{4}$ in $10 \mathrm{mM}$ Tris buffer ( $\mathrm{pH} \mathrm{7.6)]} \mathrm{at} 30^{\circ} \mathrm{C}$, as previously described (Mcbride and Baker, 1996). To observe colony-spreading, bacteria were grown on PY2 agar medium (2 $\mathrm{g}$ peptone, $0.5 \mathrm{~g}$ yeast extract, $10 \mathrm{mg} / \mathrm{ml}$ agar, $\mathrm{pH} 7.3$ ) at $30^{\circ} \mathrm{C}$ (Agarwal et al., 2001).

\section{Organic Amendments to Growth Media}

A suite of mono- and polysaccharides were amended to growth media in various configurations (as described below), to evaluate colony spreading dynamics of the selected flavobacterial strains. The following substances were used in this study: pectin (Sigma P9135), D(+)glucose (Fischer Scientific 10373242), microcrystalline cellulose (M.cellulose- partially depolymerized cellulose synthesized from an $\alpha$-cellulose precursor, Merck 
102331), D(-)arabinose (Acros 161451000), glucomannan (Megazyme P-GLCML), L-rhamnose (Sigma 83650) and $\mathrm{D}(+)$-galacturonic acid monohydrate (Sigma 48280-5G-F), polyethylene glycol (PEG) 8000 (Amresco 0159). All substances were dissolved and suspended to $2 \%$ final concentration in double distilled water (DDW), unless indicated otherwise. Glucose, arabinose, rhamnose, and galacturonic acid (titrated to $\mathrm{pH}$ 7) were dissolved and filtered through a 0.22 -micron filter. Pectin was dissolved in DDW heated at $80^{\circ} \mathrm{C}$, and subsequently filtered through 0.45 -micron filters. M.cellulose, and glucomannan were mixed with DDW heated to $50^{\circ} \mathrm{C}$ and then autoclaved for $20 \mathrm{~min}$.

\section{Flavobacterial Growth on Various Plant-Derived Poly- and Mono-Saccharides}

The selected plant-derived poly- and mono-saccharides were amended to the PY2 agar plates in two manners: (i) to test the effect of specific carbon sources on the directional proliferation of flavobacteria, $10 \mu \mathrm{l}$ of the selected compounds were thinly applied along a line projecting outward from the center of the petri dish using a pipetor (Supplementary Figure 1); (ii) to test the effect of specific carbon sources on the general proliferation of flavobacteria, $500 \mu \mathrm{l}$ from each $2 \%$ sugar solution were uniformly smeared over the entire petri dish (Figures 1A,C, 2). Non-soluble substances such as M.cellulose were vigorously vortexed and dispensed using a cut tip. Where two sugars were used (i.e., rhamnose+ galacturonic acid) we added $250 \mu \mathrm{l}$ of each. In all cases, plates were left to dry overnight after adding organic amendments. Flavobacteria were incubated on CYE media overnight, colonies were harvested and subsequently diluted in $200 \mu \mathrm{l}$ saline to $0.6-1$ OD $\left(5 \times 10^{9}-1.12 \times 10^{10}\right.$ cells), vortexed well, and $2 \mu \mathrm{l}$ were spotted in the center of PY2 agar covered or streaked with the selected plant-derived poly- and mono-saccharides as indicated above. Plates were left to dry for $15 \mathrm{~min}$ and then incubated for $48 \mathrm{~h}$ at $30^{\circ} \mathrm{C}$. The colony area or the length of expansion (in $\mathrm{cm}$ ) were measured using Fiji (Schindelin et al., 2012) and statistical analyses were calculated using JMP, Version Pro 14 (SAS Institute Inc., Cary, NC, United States, 1989-2019). Differences between length/area were considered as significantly different when $p<0.05$ in Tukey HSD test unless indicated differently.

\section{Live Imaging Fluorescent Microscopy Experiments}

To visualize the effect of different mono- and polysaccharides on F. johnsoniae colony expansion, we filled the wells of a 24 well plate with $500 \mu \mathrm{l}$ of PY2 agar. Subsequently, $10 \mu \mathrm{l}$ of the mono- and polysaccharides $(2 \%)$ or the control (DDW) were gently applied to the wells in triplicates, plates were rotated for $1 \mathrm{~h}$ and dried overnight at room temperature. A 30G needle (KDL 16-0310) was used to seed the bacteria in the center of each well by punching an agar plate with a 24 h grown colony. Microscopic imaging was performed using a NIKON eclipse $\mathrm{Ti}$ microscope (Nikon, Japan) equipped with a ProScan motorized $\mathrm{XY}$ stage, an HF110A system (enabling rapid switching of emission filters) (Prior Scientific, MA, United States) and a temperature-controlled stage incubator (on $25^{\circ} \mathrm{C}$ ) (LAUDA ECO RE 415, Korea). Bright field illumination was provided by a cool LED pE-100A (Cool LED, United Kingdom). Excitation light for epifluorescence microscopy was provided by a Spectra $\mathrm{X}$ light engine (Lumencor, United States). Imaging was performed using a long working distance $40 \mathrm{X}$ objective (NA 0.6) (Nikon, Japan). Images were captured at $2 \mathrm{~h}$ intervals for $44 \mathrm{~h}$ using an ANDOR zyla 5.5 MP sCMOS camera (Oxford Instruments, United Kingdom).

Images were processed using the NIS elements AR 4.6 (64 bit) software package (Nikon, Japan) and Fiji (Schindelin et al., 2012). Fluorescence level was normalized to the initial measured value (to avoid differences in the initial load of seeded bacteria) and to the maximal fluorescence on PY2 media amended with DDW (to reduce variability of GFP fluorescence levels between movies). The population growth dynamic of GFP-F. johnsoniae on each substance computed using Fiji's time series analyzer plugin, and average fluorescence density profiles of the expanding population over time was quantified using $\mathrm{JMP}^{\circledR}$, Version Pro 14. (SAS Institute Inc., Cary, NC, United States, 1989-2019).

\section{Proteomic Sample Preparation}

Wild-type F. johnsoniae, was grown on PY2 agar plates smeared either with $500 \mu \mathrm{l}$ of $2 \%$ pectin or with DDW, in triplicates. After $48 \mathrm{~h}$, bacteria were scraped from plates in $1 \mathrm{ml}$ of $4^{\circ} \mathrm{C} \mathrm{PBS}$ and centrifuged for $10 \mathrm{~min}, 4500 \mathrm{rpm}$ in $4^{\circ} \mathrm{C}$. Supernatant was discarded and bacterial pellets were processed.

Samples were subjected to in-solution tryptic digestion using a modified Filter Aided Sample Preparation protocol (FASP). Sodium dodecyl sulfate buffer (SDS) included: 4\% (w/v) SDS, $100 \mathrm{mM}$ Tris/HCl pH 7.6, 0.1M DTT. Urea buffer (UB): $8 \mathrm{M}$ urea (Sigma, U5128) in $0.1 \mathrm{M}$ Tris/ $\mathrm{HCl} \mathrm{pH} 8.0$ and $50 \mathrm{mM}$ Ammonium Bicarbonate. Bacterial cell pellets were lysed in SDS buffer. Lysate was centrifuged at $16,000 \mathrm{~g}$ for $10 \mathrm{~min}$. Fifty microgram total protein were mixed with $2 \mathrm{~mL} \mathrm{UB}$, loaded onto $30 \mathrm{kDa}$ molecular weight cutoff filters (Sartorius VS15RH22) and centrifuged. A total of $1.5 \mathrm{ml}$ of UB were added to the filter unit, and centrifuged at $14,000 \mathrm{~g}$ for $40 \mathrm{~min}$. Proteins were alkylated using iodoacetamide (10 $\mathrm{mM}$ final concentration) and washed twice with Ammonium Bicarbonate. Trypsin was then added (50:1 protein amount:trypsin) and samples incubated at $37^{\circ} \mathrm{C}$ overnight, followed by a second trypsin digestion for $4 \mathrm{~h}$ at $37^{\circ} \mathrm{C}$. Digested peptides were then collected in a clean tube by centrifugation, acidified with trifloroacetic acid, desalted using HBL Oasis (Waters 094225), speed vacuumed to dryness and stored in $-80^{\circ} \mathrm{C}$ until analysis. All chemicals used were from Sigma-Aldrich, unless stated otherwise. Sample preparation and initial statistical analysis was performed at the Nancy and Stephen Grand Israel National Center for Personalized Medicine, The Weizmann Institute of Science, Rehovot, Israel.

\section{Liquid Chromatography and Proteomics Analysis}

Each sample was loaded and analyzed using split-less nano-Ultra Performance Liquid Chromatography (10 kpsi nanoAcquity; 



FIGURE 1 | Impact of plant-derived poly- and mono-saccharides on proliferation of flavobacteria. Image (A) and quantification (B) of colony area of F. johnsoniae colony expansion on PY2 agar amended with different mono- and polysaccharides: arabinose, glucose, M.cellulose (microcrystalline cellulose), pectin and the no sugar (DDW control), after $48 \mathrm{~h}$ incubation at $30^{\circ} \mathrm{C}(N=4)$. Figure represents one experiment (out of four) with three technical repeats in each. Error bars represents standard error. Image (C) and quantification (D) of colony expansion on PY2 agar of wild-type (WT) and gliding mutants ( $\Delta$ gldJ) of $F$. johnsoniae and Flavobacterium sp. F52, amended with DDW (no sugar) or $2 \%$ pectin after $48 \mathrm{~h}$ incubation at $30^{\circ} \mathrm{C}(\mathrm{N}=3)$. Colony area was measured using Fiji. Letters indicate statistical significance calculated using ${ }^{\circledR}$ JMP Pro14, was considered significant if $p<0.05$ by Tukey HSD. Error bars represents standard error.

Waters, Milford, MA, United States). The mobile phase was: (A) $\mathrm{H}_{2} \mathrm{O}+0.1 \%$ formic acid and (B) acetonitrile $+0.1 \%$ formic acid. Desalting of the samples was performed online using a Symmetry C18 reversed-phase trapping column (180 $\mu \mathrm{m}$ internal diameter, $20 \mathrm{~mm}$ length, $5 \mu \mathrm{m}$ particle size; Waters). The peptides were then separated using a T3 HSS nano-column (75 $\mu \mathrm{m}$ internal diameter, $250 \mathrm{~mm}$ length, $1.8 \mu \mathrm{m}$ particle size; Waters) at $0.35 \mu \mathrm{L} / \mathrm{min}$. Peptides were eluted from the column into the mass spectrometer using the following gradient: $4-20 \% \mathrm{~B}$ in $155 \mathrm{~min}, 20-90 \%$ B in $5 \mathrm{~min}$, maintained at $90 \%$ for $5 \mathrm{~min}$ and then back to initial conditions. ULC/MS grade solvents were used for all chromatographic steps. Each sample was analyzed on the instrument separately in a random order in discovery mode. Raw data was searched against the F. johnsoniae protein databases, to which a list of common lab contaminants was added. Database search was done using the Mascot algorithm, and quantitative analysis was performed using the Expressionist software from GeneData. A Student's T-test based on log-transformed intensity values was performed determine significant differences in protein expression between colonies grown with and without pectin. As a rule of thumb we consider significant differences to be $>1$ peptide per protein, fold change $>2$ or $<0.5$, and $<0.05 p$-value. Proteins were functionally annotated using RAST (Rapid Annotations using Subsystems Technology) (Overbeek et al., 2014).

Twenty-five pectin-induced proteins were selected based on high fold change between PY2 agar coated with pectin vs. PY2 agar coated with DDW and statistical significance (proteins without annotation were removed from this analysis). Gene abundance across the dataset was normalized to $100 \%$ for each gene, and a heatmap was created using Plotly technologies Inc. ${ }^{1}$.

The mass spectrometry proteomic data was deposited to the ProteomeXchange Consortium through the PRIDE partner repository (Perez-Riverol et al., 2019) under the dataset identifier PXD023649.

\section{RNA Extraction}

To assess the expression of selected genes in the presence of pectin, total RNA was extracted from $F$. johnsoniae cells grown for $48 \mathrm{~h}$ at $30^{\circ} \mathrm{C}$ on PY2 plates covered with $500 \mu \mathrm{l}$ of DDW or $2 \%$ pectin as described above. For each plate, bacteria were

\footnotetext{
${ }^{1}$ https://plotly.com/
} 




FIGURE 2 | Impact of pectin precursors (galacturonic acid and rhamnose) on proliferation of flavobacteria. Graphic description of $F$. johnsoniae colony area on PY2 agar amended with DDW, pectin galacturonic acid, rhamnose and galacturonic acid, and rhamnose incubated at $30^{\circ} \mathrm{C}$ for $48 \mathrm{~h}(N=8)$. Statistical significance was calculated using JMP Pro $14^{\circledR}$, and means was considered significant when $p<0.05$ by Tukey HSD. Error bars represents standard error.

suspended in $1 \mathrm{ml}$ cold $\left(4^{\circ} \mathrm{C}\right)$ PBS buffer, washed once in cold PBS, centrifuged for $2 \mathrm{~min}$ at $18,000 \mathrm{~g}$, resuspended in TE buffer supplemented with $0.4 \mathrm{mg} / \mathrm{ml}$ lysozyme and then incubated for $10 \mathrm{~min}$ at room temperature. RNA was subsequently extracted from cells using the TRIzol reagent (TRIzol $^{\circledR}$ Invitrogen $^{\mathrm{TM}}$, \#15596026), following the manufacturer's instructions. Residual DNA was removed from the RNA samples by digesting with RQ1 DNAse (Promega M6101A) at $37^{\circ} \mathrm{C}$ for $40 \mathrm{~min}$. For the real-time experiments, cDNA was synthesized using 50 ng of DNAse treated RNA, with $1 \mu$ l of random primers (Promega C118A). Synthesis of single strand CDNA was achieved using ImProm-II ${ }^{\mathrm{TM}}$ Reverse-Transcriptase (Promega, Madison, WI, United States).

The integrity and concentration of the extracted RNA and cDNA, was examined with a Qubit ${ }^{\mathrm{TM}} 3.0$ Fluorometer (Thermo Fisher Scientific, United States) using reagents and protocols supplied by the manufacturer, and by electrophoresis of samples on a $0.8 \%$ agarose gel.

\section{Quantitative PCR Assessment of Gene Expression Levels}

The expression of 10 genes encoding for proteins found to be significantly induced on pectin in the proteomic analyses were analyzed using quantitative real-time PCR (qPCR). Primers for qRT-PCR experiments (Supplementary Table 5) were constructed based on the $F$. johnsoniae genome sequence and were pre-designed using the PrimerQuest ${ }^{\circledR}$ tool (Integrated DNA Technologies, United States). Triplicate cDNA samples for each of the treatments (with or without pectin) were diluted and $2 \mathrm{ng}$ was used in a $20 \mu \mathrm{l}$ final reaction volume together with $10 \mu \mathrm{l}$ Fast SYBR ${ }^{\mathrm{TM}}$ green PCR master mix (Thermo Fisher Scientific), $100 \mathrm{nM}$ each of forward and reverse primers, DDW and $1 \mu \mathrm{l}$ of template cDNA. Amplification was carried out on a StepOnePlus real-time PCR thermocycler (Applied Biosystems, Foster City, CA, United States) using the following program: heat activation of DNA polymerase at $95^{\circ} \mathrm{C}$ for $3 \mathrm{~min}$ and 40 cycles at $95^{\circ} \mathrm{C}$ for $5 \mathrm{~s}$ for denaturation and primer annealing and extension at $60^{\circ} \mathrm{C}$ for $30 \mathrm{~s}$. A melting curve was produced to confirm a single gene-specific peak and to detect primer-dimer formation by heating the samples from 60 to $95^{\circ} \mathrm{C}$ in $0.3^{\circ} \mathrm{C}$ increments. For each gene, PCR gene amplification was carried out using three independent biological replicates. Expression of each of the targeted genes was normalized to that of three alternative housekeeping genes (16S rRNA), DNA gyrase subunit B (gyrB, EC 5.99.1.3), and the electron transfer flavoprotein, alpha subunit (ETF) threonine synthase (EC 4.2.3.1). These genes were selected because there was no detected difference in their expression when grown on PY2 media amended with pectin vs. DDW in the proteomic analysis. The relative abundance of each target gene relative to a reference gene was determined according to the method described previously (Livak and Schmittgen2001). Concentrations and $\Delta \Delta \mathrm{CT}$ values were calculated and analyzed with the StepOne software v2.3 (Applied Biosystems, Foster City, CA, United States). Concomitant "no-RT" reactions, lacking reverse transcriptase, were performed for each sample and run to confirm absence of DNA contamination, as well as no template controls (NTCs) to confirm lack of contamination. Reaction efficiency was monitored by means of an in internal standard curve using a 10 -fold dilution of DNA ranging from 0.01 to $10 \mathrm{ng}$ of DNA per reaction, in triplicates. Efficiency was between 92.1 and $97.2 \%$ for all primers, and R2-values were greater than 0.99 . Data analysis was conducted using the StepOne software v2.3 (Applied Biosystems, Foster City, CA, United States).

\section{RESULTS}

\section{Growth of Flavobacterium Strains on Various Carbon Sources}

We evaluated growth dynamics of flavobacteria on rich media (PY2 agar) coated with selected plant-derived poly- 
and mono-saccharides (Figure 1A). Colony expansion of F. johnsoniae on PY2 agar media coated with pectin was close to five times higher than on the same media coated with other analyzed mono- and polysaccharides or with DDW, (control) ( $p<0.05$, Tukey-Kramer HSD test) (Figure 1B). Wild-type (WT) and gliding/typeIX secretion system mutants $(\Delta g l d J)$ of $F$. johnsoniae and the pepper root isolate Flavobacterium sp. F52 were inoculated in the center of PY2 agar media amended with or without pectin (Figure 1C). When grown on pectin, WT colonies of both Flavobacterium strains significantly expanded after $48 \mathrm{~h}$ of incubation, while growth was lower in the control without pectin (DDW). In contrast, gliding mutant $(\Delta g l d J)$ colonies of both flavobacterial strains did not expand (Figures 1C,D), indicating that the gliding apparatus is a prerequisite for pectin-induced colony expansion.

\section{Dose-Dependent Pectin Facilitated Colony Expansion}

To determine whether expansion on pectin is dose dependent, F. johnsoniae and Flavobacterium sp. F52 strains were inoculated at the center of PY2 agar media plates streaked with pectin at final concentrations of $0.5,1,2$, and $4 \%$. For all the examined pectin concentrations colonies radiated along the pectin streaks, but expansion was more significant on 2 and $4 \%$ pectin $(p<0.05$,Tukey-Kramer HSD test) (Supplementary Figure 1).

Since galacturonic acid and rhamnose are the two major components of pectins, we examined the colony expansion of F. johnsoniae on PY2 agar coated with $2 \%$ titrated galacturonic acid, 2\% rhamnose, a combination of galacturonic acid and rhamnose, $2 \%$ pectin and DDW. F. johnsoniae expansion on galacturonic acid, rhamnose (alone or combined) did not facilitate significant colony expansion $(p<0.05$, TukeyKramer HSD test) in contrast to colonies that were grown on pectin (Figure 2).

\section{Temporal Dynamics of Pectin Induced F. johnsoniae Colony Expansion}

The expansion of green fluorescent protein (GFP)-labeled F. johnsoniae on PY2 agar coated with glucose, M.cellulose, glucomannan, Peg8000, pectin, or DDW (without sugar amendment), was visualized at a higher resolution using timelapse microscopy. Colony morphology after $32 \mathrm{~h}$, on each tested substance is presented in Figure 3A.

Growth dynamics were clearly affected by the sugar type. Expansion on pectin was characterized by a relatively long lag phase. However following this stage, colonies rapidly expanded and after $22 \mathrm{~h}$, the fluorescent signal of colonies grown on pectin surpassed both the control (without sugar amendment) and the glucose and other amended compounds, after $36 \mathrm{~h}$ (according to Student T-test test). Plates coated with polyethylene glycol (PEG8000) served as an additional control to rule out mechanosensitivity associated with substrate stiffness (Tchoufag et al., 2019), since its viscosity is similar to that of pectin. Colony expansion on Peg8000 was similar to the DDW control without amended sugars, suggesting that effects were specific to pectin. Growth on pectin facilitated multiple ring-like microstructures that resemble previously described "raft" structures (Gorski et al., 1993; Figure 3B and Supplementary Movie 1). Conversely, expansion of colonies on glucose did not display this bi-phasic expansion. While bi-phasic growth was observed in all of the nonamended and amended plates, this phenomenon was most pronounced in the pectin-amended plates (Supplementary Movie 1). Bacterial colonies grown on glucose expanded the least resulting in compact, small colonies with less ringed structures, suggesting that glucose has an inhibitory effect on F. johnsoniae motility and possibly growth as was previously demonstrated (Figure 3C; Wolkin and Pate, 1984; Imamura et al., 2018). The most significant expansion observed between 6 and $20 \mathrm{~h}$ was on M.cellulose, but the colonies grown on glucomannan and pectin proliferated at later times, and the colonies grown on pectin reached the greatest intensity at $44 \mathrm{~h}$ (Figure 3C), surpassing the colonies grown on other sugar sources $(p<0.05$,TukeyKramer HSD test). The high sensitivity of the fluorescence detection enabled us to visualize lateral colony expansion on M.cellulose, which was less visible on agar plates (Figure 1A and Supplementary Movie 1).

We further evaluated the pectin-induced bi-phasic expansion described above. An initial peak in fluorescence occurred at $20 \mathrm{~h}$, and a second peak at $36 \mathrm{~h}$ (Figure 3D). After $20 \mathrm{~h}$ of growth, total fluorescence was highest in cells grown on pectin, glucomannan, and M.cellulose, and lowest on glucose $(p<0.05$, Tukey-Kramer HSD test).

Next, we estimated the velocity of colony expansion on the selected mono- and polysaccharides by measuring the time it took the colonies to cross three radials $(3,6$, and $9 \mathrm{~mm}$ ), and subsequently calculating the mean velocity from circle to circle (Figure 3E). In the first $1.5 \mathrm{~mm}$ radius, the estimated colony expansion velocity was higher in pectin and M.cellulose and similar on the rest of the substances. Between 1.5 and $3 \mathrm{~mm}$, colony expansion on pectin and glucomannan increased. Colony expansion velocity in the outer circle was similar for all substance except glucose, with pectin still exhibiting the fastest expansion rates of all the tested mono- and polysaccharides although this was not statistically significant (Figure 3F). Thus, F. johnsoniae expanded faster on pectin than on any of the other tested carbon sources (Figure 3G). Collectively, we conclude that the bi-phasic growth of $F$. johnsoniae is very prominent on pectin. In summary, after an initial lag phase, F. johnsoniae is characterized by a rapid expansion phase, followed by a slower growth phase where cells appear to spread less and gain biomass.

\section{Specific TonB/Sus Transducers Are Expressed in Response to Growth on Pectin}

In order to gain greater insight into the molecular mechanisms associated with flavobacterial colony expansion on pectin, 
A<smiles>CC1(C)CCCCCCCCC1</smiles>



M.Cellulose

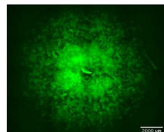

PEG8000

C



E



B
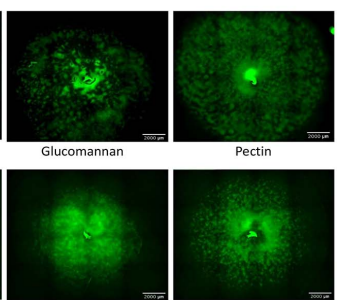

Glucose

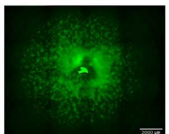

No Sugars


PEG8000
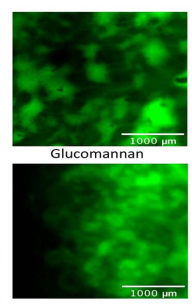

Glucose
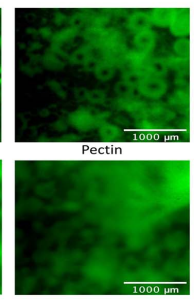

No Sugars

D

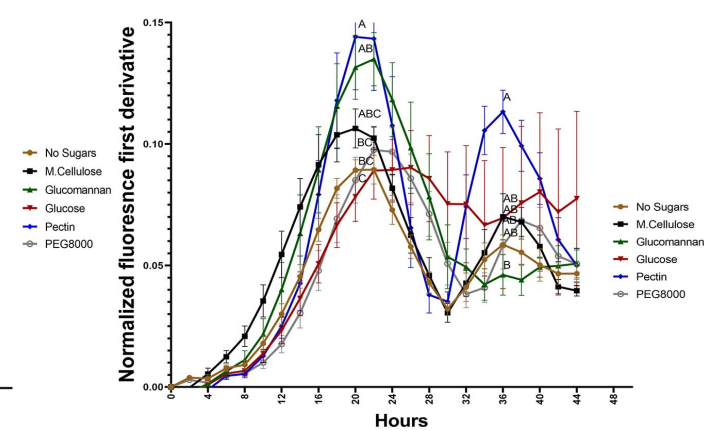

F

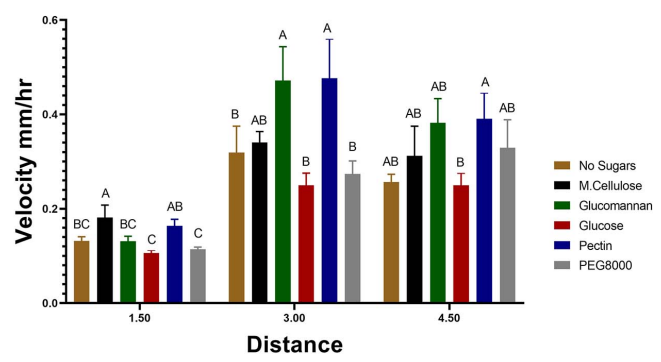

G



FIGURE 3 | Temporal dynamics of flavobacterial proliferation on polysaccharides using live imaging microscopy. (A) Morphology of GFP-labeled F. johnsoniae colonies on PY2 agar amended with selected plant-derived poly- and mono-saccharides: M.cellulose, glucomannan, pectin, glucose, and PEG8000 and DDW (no sugar control). Bacteria were inoculated in the center of PY2 agar coated with the indicated substances (schematically described in the insert). Images show colony morphology after 32 h. (B) Enlarged image of GFP-F. johnsoniae colony morphology after 16 h of growth on the selected plant-derived poly- and mono-saccharides as indicated in (A). (C) Growth rates of GFP-F. johnsoniae colonies on the selected plant-derived poly- and mono-saccharides. Data was normalized as described in section "Materials and Methods." Differences in the average colony fluorescence intensity after $44 \mathrm{~h}$ was compared and considered significant if $p<0.05$ by Tukey HSD (indicated by letters). Data includes means and data from three biological replicates composed of three technical repeats in each. (D) Temporal dynamics of GFP-F. johnsoniae growth rates. Growth was compared at the peaks (20 and $36 \mathrm{~h}$ ) and considered significant if $p<0.05$ by Tukey HSD. (E) Schematic diagram showing the three characterized regions of interest (ROI- 1.5, 3, and $4.5 \mathrm{~mm}$ radii) used to evaluate of bacterial expansion rates. (F) Estimated expansion rates of GFP-F. johnsoniae on the selected plant-derived poly- and mono-saccharides. Velocity was estimated by expansion time in hours taken to cross known ROls as indicated in (E). Differences between treatments were considered significant when $p<0.05$ by Student $T$-test (G) Estimated expansion time relative to estimated growth of GFP-F. johnsoniae on the selected plant-derived poly- and mono-saccharides. Colored circles mark time (h) for bacteria to cross the $4.5 \mathrm{~mm}$ radius on each substance as calculated in (F). All error bars represents standard error. 
A

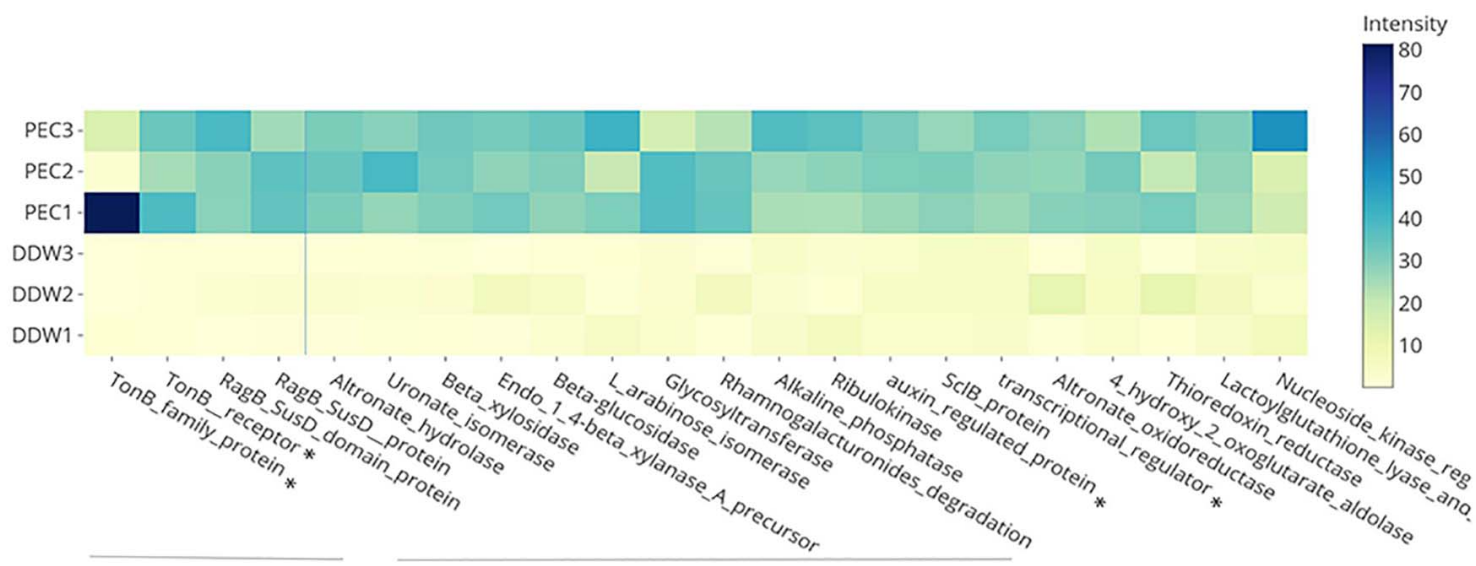

TonB

related

B

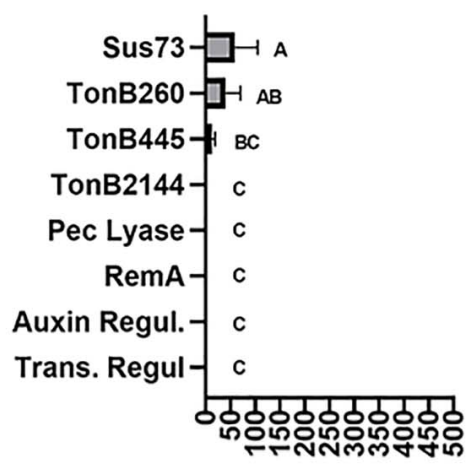

Carbohydrate

metabolism related



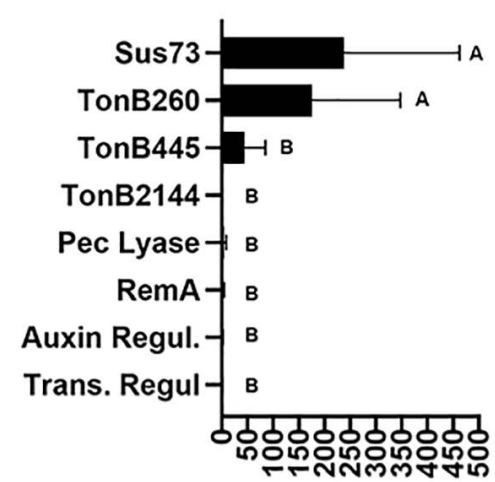

FIGURE 4 | Pectin induced flavobacterial genes and proteins. (A) Differential expression of the 25 most substantial pectin induced proteins based on proteomic analysis of $F$. johnsoniae colonies grown on PY2 medium amended with pectin relative to colonies grown on identical media amended without pectin (DDW). Heat map shows triplicates for each treatment. All described proteins are statistically significant $(p<0.05)$. The asterisk $\left(^{*}\right)$ marks proteins that were examined by qPCR. From left to right: TonB450, TonB260, auxin regulator, transcriptional regulator. (B) The mRNA expression level of selected proteins Sus73 (SHH12854.1), TonB260 (WP_012026229.1), TonB445 (WP_012022294.1), TonB2144 (WP_012026069.1), auxin regulator (WP_012023111.1), transcriptional regulator (WP_012022876.1), pectate lyase (WP_012026072.1), and RemA (WP_012022896.1) shown to be induced in the proteomic analysis described in (A), using quantitative real-time PCR (qPCR). Fold changes in mRNA levels of the target genes were normalized against the 16SrRNA gene (left), the Electron transfer Flavoprotein, alpha subunit (WP_012023552.1) (center), and the DNA gyrase subunit B (WP_012024321.1) (right). Change in target genes fold change RNA expression was calculated using the $2^{-\Delta \Delta C T}$ method and statistical significance $(p<0.05)$ by Student $T$-test. Error bars represent standard errors of six independent experiments based on two independent RNA extractions.

we conducted a proteomic assay in which we examined differential intracellular protein expression after $44 \mathrm{~h}$ growth of F. johnsoniae on PY2 agar coated with pectin relative to the same rich media coated with DDW. Eighty-three proteins were more expressed on pectin, whereas 43 were more expressed on the DDW control (Supplementary Tables 1A,B). A substantial proportion of these proteins were unassigned, while a large fraction of the proteins $(17,22$, and $37 \%$ of KEGG, SEED, and EggNog annotations, respectively) were associated with carbohydrate metabolism (Supplementary Figures 2A-C). Of the 25 most markedly pectin-induced proteins identified, 13 were involved in polysaccharide uptake, processing and metabolism, including four Sus $\mathrm{C} / \mathrm{D}$ related proteins (Figure 4A). Other pectin-induced proteins included a novel transcriptional regulator (12-fold higher on pectin) and a protein associated with auxin regulation (26-fold higher on pectin) (Supplementary Tables 1A,B). Interestingly, none of the differentially synthesized proteins were gliding related (Supplementary Table 2).

Of the 44 previously described SusC and 42 SusD homologs identified in the F. johnsoniae genome (McBride et al., 2009), 27 SusC and 15 SusD proteins were detected in the proteomic analysis, in addition to 610 proteins encoding flanking genes surrounding these Sus proteins encoding genes that constitute PUL clusters seemingly associated with glycan metabolism. Of these, three SusC and six SusD proteins along with 31 associated PUL genes encoding proteins (forming four gene clusters Supplementary Table 3) were significantly induced in response to growth on pectin in the proteomic analysis (Supplementary Table 4). 
In order to validate the proteomic results, F. johnsoniae cells were again grown on PY2 agar coated with pectin or DDW as described in the proteomic analysis, and the expression of eight genes (Supplementary Table 5) were evaluated by quantitative real time PCR. Pectin did not induce expression of remA (WP_012022896.1) encoding for an adhesion protein involved in gliding motility (not evaluated in the proteomic analysis since it is an extra-membrane protein), indicating that synthesis of this protein is not enhanced on pectin at the tested time point. Expression of genes encoding for the novel transcriptional regulator (Trans. Regul WP_012022876.1), pectate lyase (Pec lyase WP_012026072.1), putative auxin-regulated annotated protein (Auxin WP_012023111.1), and tonB 2144 (WP_012026069.1), were also not differentially expressed on pectin-coated media despite the fact that they were significantly induced on pectin in the proteomic analysis. Among the examined TonB/SusC related genes, tonB 260 (WP_012026229.1) and sus73 (SHH12854.1) were significantly upregulated (60-100fold, $p<0.05$ Tukey-Kramer HSD test) while TonB 445 (WP_012022294.1) was substantially upregulated (10-20-fold) but not statistically significant (Figure 4B). tonB260 and sus73 are part of an 18-gene cluster, of which all of the encoded proteins were upregulated in the presence of pectin in the proteomic analysis (cluster 1-Supplementary Table 3). Using two different prediction tools, the TonB260 and Sus73 encoding genes were mapped to the same operon together with a gene encoding for the hydrolytic enzyme polygalacturonase that cleaves the $\alpha(1-4)$ bonds between adjacent galacturonic acids within the homogalacturonic acid backbone of pectin (Supplementary Table 6).

\section{DISCUSSION}

\section{Pectin Facilitates Rapid Spreading of Flavobacteria}

Results from this study demonstrated that flavobacteria not only metabolize complex plant cell wall-derived glycans but that these polysaccharides (particularly pectin) facilitate rapid spreading of flavobacteria over solid surfaces, even when carbon was not limited. Both the pattern and the extent of F. johnsoniae colony expansion was dictated by the carbon source supplemented to the growth media. The expansion on rich media coated with pectin and glucomannan was rapid, patchy, non-uniform and sparse relative to colonies grown on rich media coated with glucose or DDW. On a microscopic level, this rapid expansion was characterized by ring like micro-structures, resembling previously described rafts or dendrites (Gorski et al., 1993; Sato et al., 2021). While the connection between the carbon source and flavobacterial colony expansion is not clear, the fact that we did not observe rapid expansion or raftlike structures in flavobacteria grown on PEG8000, indicates that the phenomenon is specifically attributed to the chemical attributes of pectin and not to physical properties (viscosity) of the growth medium.
While previous studies indicate that $F$. johnsoniae cannot utilize non-depolymerized cellulose or M.cellulose a sole carbon source (McBride et al., 2009), we demonstrate that colonies of F. johnsoniae did expand on rich (PY2) media amended with M.cellulose in microplate experiments using fluorescent microscopy. It appears that the bacteria propagated on the microcrystal surfaces without creating a dense colony structure, suggesting that the bacterium glides along the fibers without actually metabolizing them. In contrast to pectin, growth on glucose inhibited propagation of flavobacteria as previously reported (Wolkin and Pate, 1984; Imamura et al., 2018). Specifically, glucose was shown to inhibit colony spreading via MfsA which encodes a major facilitator superfamily (MFS) transporter (Imamura et al., 2018), resulting in absence of raft microstructures that are formed when grown on other carbon sources. Nonetheless, glucose did not inhibit gliding motility in general (Wolkin and Pate, 1984; Gorski et al., 1993) and spreading on glucose was recently found to be in inverse correlation to agar concentration and characterized by unique windmilllike structures under media of specific glucose-agar levels (Sato et al., 2021).

Pectin, but not pectin monomers (D-galacturonic acid and L-rhamnose) significantly facilitated colony expansion in a dose dependent manner. Rhizosphere and phyllosphere associated flavobacterial genomes are genetically compatible for metabolizing plant-associated polysaccharides. Specifically, their genome contains many genes encoding glycohydrolases, polysaccharide lyases, and esterases and can efficiently degrade complex biopolymers (McBride et al., 2009) and plantassociated flavobacterial genomes have an over-representation of genes involved in the metabolism of pectin (Kolton et al., 2013). Beside the ability to degrade pectin and consume it, the reduced ability of flavobacteria colonies to spread on pectin monomers (rhamnose or/and galacturonic acid) suggests that the original spatial organization of plant cell wall components are important for recognition and expansion on it. Due to the importance of pectin and other glucans in plant cell walls, we hypothesize that soil and root-associated bacteria have devised different strategies to colonize it and use it as a cue for colonization and expansion on root surfaces.

For example, Flexibacter sp. FS-1 was not able to glide on agarose alone but did glide on agarose amended with 1\% pectin (Arlauskas and Burchard, 1982). Purified Arabidopsis polysaccharides (arabinogalactan, pectin, or xylan) triggered biofilm formation in Bacillus subtilis when added to rich media and induced root colonization (Beauregard et al., 2013). Similarly, addition of pectin and sucrose to the media of the PGPR Bacillus amyloliquefaciens strain SQY 162, increased bacterial abundance, induced biofilm formation and improved the ability of the amended bacterium to suppress tobacco bacterial wilt disease (Wu et al., 2015). In the symbiotic nitrogen fixing bacterium Rhizobium leguminosarum, glucomannan-mediated attachment was important for legume infection and nodulation (Williams et al., 2008). 


\section{Growth on Pectin Is Bi-Phasic}

Live-imaging fluorescent microscopy revealed that $F$. johnsoniae growth on PY2 media coated with different mono- and polysaccharides was bi-phasic in nature, with an initial phase of rapid expansion, followed by biomass production within the colonized area. This bi-phasic growth pattern, which was most pronounced on pectin, resembles previously described models in motile Escherichia coli, which depicted an initial expansion phase, where "pioneer" bacteria with high velocity advance in front of the colony, followed by a second phase, where "settler" bacteria grow and replicate locally (Cremer et al., 2019; Liu et al., 2019). We hypothesize that plant-derived polysaccharides and especially pectin may serve as signal that facilitates the expansion of "pioneer" cells, and later as carbon sources that support growth of "settlers."

\section{Pectin Does Not Induce Gliding-Associated Proteins}

Despite the substantial evidence that pectin stimulated flavobacterial colony expansion, it did not induce expression of known gliding motility proteins (although not all were identified in the proteomic analyses) or proteins associated with chemotaxis, nor did it induce expression of remA, encoding the lectin binding, flavobacterial cell surface adhesin involved in gliding (Shrivastava et al., 2012). While the specific correlation between expansion on pectin and the unique flavobacterial gliding motility mechanism was not determined in this study, it is evident that the latter is required, because gliding deficient $(\Delta g l d J)$ flavobacterial mutants did not expand on pectin. The gliding machinery might be induced in the earlier phase of the response to pectin, in which we observed intensive bacterial motility. Alternatively, pectin might facilitate gliding in a protein expression-independent manner or induce other components of the gliding machinery not identified in our proteomic analyses. A recent study identified two flavobacterial lipoproteins linked to both biofilm formation and gliding motility (Sato et al., 2021), supporting the notion that other currently hypothetical proteins may also be linked to colony spreading.

Based on proteomic and subsequent $\mathrm{qPCR}$ gene expression validation, we believe that the pectin-induced flavobacterial expansion observed in this study is at least partially mediated by the induction of specific TonBassociated PULs. Extrapolation of these lab-based results to flavobacterial-root interactions, suggest a link between niche recognition, colony expansion and metabolic fitness. Similar induction of TonB and PUL was observed in marine flavobacteria as response to phytoplankton blooms characterized in decomposition of alga-derived organic matter (Teeling et al., 2012).

A few studies have previously linked TonB proteins with motility, attachment or plant-bacterial interactions. TonB was associated with twitching motility in Pseudomonas aeruginosa (Huang et al., 2004), and was also found to play a role in the ability of Acinetobacter baumannii to bind to the high-molecular weight glycoprotein fibronectin, indicating the capacity to bind to extracellular host proteins (Zimbler et al., 2013). In Xanthomonas campestris pv. Campestris, pectate sensed by specific TonB-dependent receptors triggered secretion of extracellular polygalacturonate. This resulted in pectin degradation and generation of oligogalacturonides (OGA) that are recognized as damage-associated molecular patterns (DAMPs), facilitating the initiation of the plant defense mechanisms (Vorhölter et al., 2012). Previous experiments showed that Pseudomonas putida mutants that lacked TonB, were deficient in their capacity to uptake iron and displayed impaired seed colonization, linking TonB to metabolic and functional fitness in plant-associated bacteria (Molina et al., 2005). The high energetic cost and substrate specificity of TonB transducers explains why the genes encoding them were induced by pectin and not constitutively expressed (Postle and Kadner, 2003; Postle, 2007). These proteins may play a pivotal role in flavobacterial-plant interactions, however, knock-out of specific ton $B$ genes in $F$. johnsoniae will be challenging due to the multitude of predicted ton $B$ genes in its genome, which suggests a high level of functional redundancy (McBride et al., 2009).

\section{Additional Pectin-Induced Proteins}

Pectin significantly induced several proteins in addition to TonB related proteins. These included an auxin-regulated protein, which is especially interesting since auxin is a major phytohormone responsible for plant growth and development, demonstrating again a possible connection between pectin sensing and flavobacterial-plant interactions. Interestingly, pectin resulted in substantial induction of a putative transcriptional regulator, suggesting pectin-induced regulation of additional genes. Knocking out or silencing this regulator can shed light on this pectin-induced downstream response, and its potential role in flavobacterial-plant interactions.

The fact that gene expression (qPCR) did not completely correlate with the proteomic data might be explained by post-translational modifications or regulation affecting protein stability, degradation and complex formation, as shown in similar cases (Flory et al., 2006; Liu et al., 2016). Alternatively, this discrepancy may be explained by a recently proposed model showing that in growing cells, mRNA can saturate ribosomes thereby limiting translation, resulting in an increase in the protein-to-DNA ratio (Lin and Amir, 2018).

\section{SUMMARY}

To summarize, we found that pectin, a prominent plant cell wall polysaccharide, facilitates expansion of flavobacteria on solid surfaces, even in the presence of nutrient-rich media. We postulate that pectin may enhance the capacity of flavobacteria to efficiently colonize and proliferate on plant surfaces. The interaction between pectin (and potentially other root glycans) and flavobacteria is mediated by induction of TonB/SusC operons and other associated PULs that facilitate metabolism of pectin. Thus, in the root environment, plant cell wall polysaccharides, 
and specifically pectin, may not only serve as a nutrient source for flavobacteria, but also as a potential environmental cue for colonization and rapid expansion along the root surface.

\section{DATA AVAILABILITY STATEMENT}

The original contributions presented in the study are included in the article/Supplementary Material, further inquiries can be directed to the corresponding author.

\section{AUTHOR CONTRIBUTIONS}

JK-C, OHS, BD, and EC secured funding, experimental design, manuscript editing. All authors contributed to the article and approved the submitted version.

\section{REFERENCES}

Agarwal, S., Hunnicutt, D. W., and McBride, M. J. (2001). Cloning and characterization of theFlavobacterium johnsoniae gliding motility GenesgldD and gldE. J. Bacteriol. 183, 4167-4175.doi: 10.1128/JB.183.14.4167-4175.2001

Alexander, B. J. R., and Stewart, A. (2001). Glasshouse screening for biological control agents of Phytophthora cactorum on apple (Malus domestica). N.Z. J. Crop Hortic. Sci. 29, 159-169.doi: 10.1080/01140671.2001.9514174

Arlauskas, J., and Burchard, R. P. (1982). Substratum requirements for bacterial gliding motility. Arch. Microbiol. 133, 137-141. doi: $10.1007 /$ BF00413527

Barret, M., Morrissey, J. P., and O'Gara, F. (2011). Functional genomics analysis of plant growth-promoting rhizobacterial traits involved in rhizosphere competence. Biol. Fertil. Soils 47, 729-743.doi: 10.1007/s00374-011-0605-x

Beauregard, P. B., Chai, Y., Vlamakis, H., Losick, R., and Kolter, R. (2013). Bacillus subtilis biofilm induction by plant polysaccharides. Proc. Natl. Acad. Sci. U.S.A. 110, E1621-E1630. doi: 10.1073/pnas.1218984110

Berendsen, R. L., Pieterse, C. M. J., and Bakker, P. A. H. M. (2012). The rhizosphere microbiome and plant health. Trends Plant Sci. 17, 478-486.doi: 10.1016/j. tplants.2012.04.001

Bodenhausen, N., Horton, M. W., and Bergelson, J. (2013). Bacterial communities associated with the leaves and the roots of Arabidopsis thaliana. PLoS One 8:e56329.doi: 10.1371/journal.pone.0056329

Braun, T. F., and McBride, M. J. (2005). Flavobacterium johnsoniae GldJ is a lipoprotein that is required for gliding motility. J. Bacteriol. 187, 2628-2637.doi: 10.1128/JB.187.8.2628-2637.2005

Bulgarelli, D., Garrido-Oter, R., Münch, P. C., Weiman, A., Dröge, J., Pan, Y., et al. (2015). Structure and function of the bacterial root microbiota in wild and domesticated barley. Cell Host Microbe 17, 392-403.doi: 10.1016/j.chom.2015. 01.011

Bulgarelli, D., Schlaeppi, K., Spaepen, S., van Themaat, E. V. L., and Schulze-Lefert, P. (2013). Structure and functions of the bacterial microbiota of plants. Annu. Rev. Plant Biol. 64, 807-838. doi: 10.1146/annurev-arplant-050312- 120106

Carrión, V. J., Perez-Jaramillo, J., Cordovez, V., Tracanna, V., de Hollander, M., Ruiz-Buck, D., et al. (2019). Pathogen-induced activation of disease-suppressive functions in the endophytic root microbiome. Science 366, 606-612.doi: 10. 1126/science.aaw9285

Cremer, J., Honda, T., Tang, Y., Wong-Ng, J., Vergassola, M., and Hwa, T. (2019). Chemotaxis as a navigation strategy to boost range expansion. Nature 575, 658-663.doi: 10.1038/s41586-019-1733-y

Dennis, P. G., Miller, A. J., and Hirsch, P. R. (2010). Are root exudates more important than other sources of rhizodeposits in structuring rhizosphere bacterial communities? FEMS Microbiol. Ecol. 72, 313-327.doi: 10.1111/j.15746941.2010.00860.x

Feng, H., Zhang, N., Fu, R., Liu, Y., Krell, T., Du, W., et al. (2019). Recognition of dominant attractants by key chemoreceptors mediates recruitment of plant

\section{ACKNOWLEDGMENTS}

We thank M. J. McBride from the University of WisconsinMilwaukee for generously providing plasmids and F. johnsoniae strains. We would also like to thank Alla UsyskinTonne, for her help with the proteomics functional annotation and Eduard Belausov for his help with the binocular based imaging. This article was published at bioRxiv as preprint, doi: https://doi.org/10.1101/2020.06. 26.174714 .

\section{SUPPLEMENTARY MATERIAL}

The Supplementary Material for this article can be found online at: https://www.frontiersin.org/articles/10.3389/fmicb. 2021.651891/full\#supplementary-material

growth-promoting rhizobacteria. Environ. Microbiol. 21, 402-415.doi: 10.1111/ 1462-2920.14472

Flory, M. R., Lee, H., Bonneau, R., Mallick, P., Serikawa, K., Morris, D. R., et al. (2006). Quantitative proteomic analysis of the budding yeast cell cycle using acid-cleavable isotope-coded affinity tag reagents. Proteomics 6, 6146-6157.doi: 10.1002/pmic.200600159

Foley, M. H., Cockburn, D. W., and Koropatkin, N. M. (2016). The Sus operon: a model system for starch uptake by the human gut Bacteroidetes. Cell. Mol. Life Sci. 73, 2603-2617.doi: 10.1007/s00018-016-2242-x

Gorski, L., Godchaux, W., and Leadbetter, E. R. (1993). Structural specificity of sugars that inhibit gliding motility of Cytophaga johnsonae. Arch. Microbiol. 160, 121-125.doi: 10.1007/BF00288713

Gunasinghe, R. N., Ikiriwatte, C. J., and Karunaratne, A. M. (2004). The use of Pantoea agglomerans and Flavobacterium sp. to control banana pathogens. J. Hortic. Sci. Biotechnol. 79, 1002-1006. doi: 10.1080/14620316.2004.11511852

Hebbar, P., Berge, O., Heulin, T., and Singh, S. P. (1991). Bacterial antagonists of Sunflower (Helianthus annuus L.) fungal pathogens. Plant Soil 133, 131140.doi: 10.1007/BF00011907

Huang, B., Ru, K., Yuan, Z., Whitchurch, C. B., and Mattick, J. S. (2004). tonB3 is required for normal twitching motility and extracellular assembly of type IV Pili. J. Bacteriol. 186, 4387-4389.doi: 10.1128/JB.186.13.4387-4389.2004

Imamura, K., Sato, K., Narita, Y., Kondo, Y., Nakane, D., Naito, M., et al. (2018). Identification of a major glucose transporter in Flavobacterium johnsoniae: inhibition of F. johnsoniae colony spreading by glucose uptake. Microbiol. Immunol. 62, 507-516.doi: 10.1111/1348-0421.12633

Janssen, P. H. (2006). Identifying the dominant soil bacterial taxa in libraries of 16S rRNA and 16S rRNA genes. Appl. Environ. Microbiol. 72, 1719-1728.doi: 10.1128/AEM.72.3.1719-1728.2006

Jiménez, D. J., Chaves-Moreno, D., and van Elsas, J. D. (2015). Unveiling the metabolic potential of two soil-derived microbial consortia selected on wheat straw. Sci. Rep. 5:13845. doi: 10.1038/srep13845

Johansen, J. E., Binnerup, S. J., Lejbolle, K. B., Mascher, F., Sorensen, J., and Keel, C. (2002). Impact of biocontrol strain Pseudomonas fluorescens CHA0 on rhizosphere bacteria isolated from barley (Hordeum vulgare L.) with special reference to Cytophaga-like bacteria. J. Appl. Microbiol. 93, 1065-1074.doi: 10. 1046/j.1365-2672.2002.01778.x

Johnston, J. J., Shrivastava, A., and McBride, M. J. (2018). Untangling Flavobacterium johnsoniae gliding motility and protein secretion. J. Bacteriol. 200:e00362-17. doi: 10.1128/JB.00362-17

Kharade, S. S., and McBride, M. J. (2015). Flavobacterium johnsoniae PorV is required for secretion of a subset of proteins targeted to the type IX secretion system. J. Bacteriol. 197, 147-158.doi: 10.1128/JB.02085-14

Kolton, M., Frenkel, O., Elad, Y., and Cytryn, E. (2014). Potential role of flavobacterial gliding-motility and type IX secretion system complex in root colonization and plant defense. Mol. Plant Microbe Interact. 27, 1005-1013.doi: 10.1094/MPMI-03-14-0067-R 
Kolton, M., Meller Harel, Y., Pasternak, Z., Graber, E. R., Elad, Y., and Cytryn, E. (2011). Impact of biochar application to soil on the root-associated bacterial community structure of fully developed greenhouse pepper plants. Appl. Environ. Microbiol. 77, 4924-4930.doi: 10.1128/AEM.00148-11

Kolton, M., Sela, N., Elad, Y., and Cytryn, E. (2013). Comparative genomic analysis indicates that niche adaptation of terrestrial Flavobacteria is strongly linked to plant glycan metabolism. PLoS One 8:e76704.doi: 10.1371/journal.pone. 0076704

Kwak, M.-J., Kong, H. G., Choi, K., Kwon, S.-K., Song, J. Y., Lee, J., et al. (2018). Rhizosphere microbiome structure alters to enable wilt resistance in tomato. Nat. Biotechnol. 36, 1100-1109.doi: 10.1038/nbt.4232

Lauber, F., Deme, J. C., Lea, S. M., and Berks, B. C. (2018). Type 9 secretion system structures reveal a new protein transport mechanism. Nature 564, 77-82.doi: 10.1038/s41586-018-0693-y

Lin, J., and Amir, A. (2018). Homeostasis of protein and mRNA concentrations in growing cells. Nat. Commun. 9:4496. doi: 10.1038/s41467-018-06714-z

Liu, W., Cremer, J., Li, D., Hwa, T., and Liu, C. (2019). An evolutionarily stable strategy to colonize spatially extended habitats. Nature 575, 664-668.doi: 10. 1038/s41586-019-1734-x

Liu, Y., Beyer, A., and Aebersold, R. (2016). On the dependency of cellular protein levels on mRNA abundance. Cell 165, 535-550.doi: 10.1016/j.cell.2016.03.014

Lugtenberg, B. J. J., and Dekkers, L. C. (1999). What makes Pseudomonas bacteria rhizosphere competent? Environ. Microbiol. 1, 9-13.doi: 10.1046/j.1462-2920. 1999.00005.x

Lundberg, D. S., Lebeis, S. L., Paredes, S. H., Yourstone, S., Gehring, J., Malfatti, S., et al. (2012). Defining the core Arabidopsis thaliana root microbiome. Nature 488, 86-90.doi: 10.1038/nature 11237

Manter, D. K., Delgado, J. A., Holm, D. G., and Stong, R. A. (2010). Pyrosequencing reveals a highly diverse and cultivar-specific bacterial endophyte community in potato roots. Microb. Ecol. 60, 157-166. doi: $10.1007 / \mathrm{s} 00248-010-9658-\mathrm{x}$

Martens, E. C., Koropatkin, N. M., Smith, T. J., and Gordon, J. I. (2009). Complex glycan catabolism by the human gut microbiota: the Bacteroidetes Sus-like Paradigm. J. Biol. Chem. 284, 24673-24677.doi: 10.1074/jbc.R109.022848

Massalha, H., Korenblum, E., Malitsky, S., Shapiro, O. H., and Aharoni, A. (2017). Live imaging of root-bacteria interactions in a microfluidics setup. Proc. Natl. Acad. Sci. U.S.A. 114, 4549-4554.doi: 10.1073/pnas.1618584114

Mcbride, M. J., and Baker, S. A. (1996). Development of techniques to genetically manipulate members of the genera Cytophaga, Flavobacterium, Flexibacter, and Sporocytophaga. Appl. Environ. Microbiol. 62, 3017-3022. doi: 10.1128/aem.62. 8.3017-3022.1996

McBride, M. J., Liu, W., Lu, X., Zhu, Y., and Zhang, W. (2014). "The Family Cytophagaceae," in The Prokaryotes, (Berlin: Springer), 577-593. doi: 10.1007/ 978-3-642-38954-2_382

McBride, M. J., and Nakane, D. (2015). Flavobacterium gliding motility and the type IX secretion system. Curr. Opin. Microbiol. 28, 72-77.doi: 10.1016/j.mib. 2015.07.016

McBride, M. J., Xie, G., Martens, E. C., Lapidus, A., Henrissat, B., Rhodes, R. G., et al. (2009). Novel features of the polysaccharide-digesting gliding bacterium Flavobacterium johnsoniae as revealed by genome sequence analysis. Appl. Environ. Microbiol. 75, 6864-6875.doi: 10.1128/AEM.01495-09

Molina, M. A., Godoy, P., Ramos-Gonzalez, M. I., Munoz, N., Ramos, J. L., and Espinosa-Urgel, M. (2005). Role of iron and the TonB system in colonization of corn seeds and roots by Pseudomonas putida KT2440. Environ. Microbiol. 7, 443-449.doi: 10.1111/j.1462-2920.2005.00720.x

Oku, S., Ayaka, K., Takahisa, T. K., and Junichi, Y. N. (2012). Identification of chemotaxis sensory proteins for amino acids in Pseudomonas fluorescens Pf0-1 and their involvement in chemotaxis to tomato root exudate and root colonization. Microbes Environ. 27, 462-469. doi: 10.1111/1462-2920.12228

Overbeek, R., Olson, R., Pusch, G. D., Olsen, G. J., Davis, J. J., Disz, T., et al. (2014). The SEED and the rapid annotation of microbial genomes using subsystems technology (RAST). Nucleic Acids Res. 42, D206-D214. doi: 10. 1093/nar/gkt1226

Perez-Riverol, Y., Csordas, A., Bai, J., Bernal-Llinares, M., Hewapathirana, S., Kundu, D. J., et al. (2019). The PRIDE database and related tools and resources in 2019: improving support for quantification data. Nucleic Acids Res. 47, D442-D450. doi: 10.1093/nar/gky1106
Pieterse, C. M., Zamioudis, C., Berendsen, R. L., Weller, D. M., Van Wees, S. C., and Bakker, P. A. (2014). Induced systemic resistance by beneficial microbes. Annu. Rev. Phytopathol. 52, 347-375. doi: 10.1146/annurev-phyto-082712-102340

Postle, K. (2007). TonB system, in vivo assays and characterization. Methods Enzymol. 422, 245-269.doi: 10.1016/S0076-6879(06)22012-3

Postle, K., and Kadner, R. J. (2003). Touch and go: tying TonB to transport. Mol. Microbiol. 49, 869-882.doi: 10.1046/j.1365-2958.2003.03629.x

Reinhold-Hurek, B., Bünger, W., Burbano, C. S., Sabale, M., and Hurek, T. (2015). Roots shaping their microbiome: global hotspots for microbial activity. Annu. Rev. Phytopathol. 53, 403-424.doi: 10.1146/annurev-phyto-082712-102342

Rudrappa, T., Czymmek, K. J., Paré, P. W., and Bais, H. P. (2008). Root-secreted malic acid recruits beneficial soil bacteria. Plant Physiol. 148, 1547-1556.doi: $10.1104 /$ pp. 108.127613

Sang, M. K., Kim, J. D., Kim, B. S., and Kim, K. D. (2011). Root treatment with rhizobacteria antagonistic to phytophthora blight affects anthracnose occurrence, ripening, and yield of pepper fruit in the plastic house and field. Phytopathology 101, 666-678.doi: 10.1094/PHYTO-08-10-0224

Sang, M. K., and Kim, K. D. (2012). The volatile-producing Flavobacterium johnsoniae strain GSE09 shows biocontrol activity against Phytophthora capsici in pepper. J. Appl. Microbiol. 113, 383-398.doi: 10.1111/j.1365-2672.2012. 05330.x

Sasse, J., Martinoia, E., and Northen, T. (2018). Feed your friends: Do plant exudates shape the root microbiome? Trends Plant Sci. 23, 25-41.doi: 10.1016/ j.tplants.2017.09.003

Sato, K., Naya, M., Hatano, Y., Kondo, Y., Sato, M., Narita, Y., et al. (2021). Colony spreading of the gliding bacterium Flavobacterium johnsoniae in the absence of the motility adhesin SprB. Sci. Rep. 11:967. doi: 10.1038/s41598-020-79762-5

Schindelin, J., Arganda-Carreras, I., Frise, E., Kaynig, V., Longair, M., Pietzsch, T., et al. (2012). Fiji: an open-source platform for biological-image analysis. Nat. Methods 9, 676-682.doi: 10.1038/nmeth.2019

Sela, N., Cytryn, E., Green, S. J., Harel, Y. M., Kolton, M., and Elad, Y. (2012). Draft genome sequence of Flavobacterium sp. strain F52, isolated from the rhizosphere of bell pepper (Capsicum annuum L. cv. Maccabi). J. Bacteriol. 194, 5462-5463.doi: 10.1128/jb.01249-12

Shrivastava, A., Johnston, J. J., Van Baaren, J. M., and McBride, M. J. (2013). Flavobacterium johnsoniae GldK. GldL, GldM, and SprA are required for secretion of the cell surface gliding motility adhesins sprb and remA. J. Bacteriol. 195, 3201-3212.doi: 10.1128/JB.00333-13

Shrivastava, A., Rhodes, R. G., Pochiraju, S., Nakane, D., and McBride, M. J. (2012). Flavobacterium johnsoniae RemA is a mobile cell surface lectin involved in gliding. J. Bacteriol. 194, 3678-3688.doi: 10.1128/JB.00588-12

Staroscik, A. M., Hunnicutt, D. W., Archibald, K. E., and Nelson, D. R. (2008). Development of methods for the genetic manipulation of Flavobacterium columnare. BMC Microbiol. 8:115.doi: 10.1186/1471-2180-8-115

Tchoufag, J., Ghosh, P., Pogue, C. B., Nan, B., and Mandadapu, K. K. (2019). Mechanisms for bacterial gliding motility on soft substrates. Proc. Natl. Acad. Sci. U.S.A. 116, 25087-25096.doi: 10.1073/pnas. 1914678116

Teeling, H., Fuchs, B. M., Becher, D., Klockow, C., Gardebrecht, A., Bennke, C. M., et al. (2012). Substrate-controlled succession of marine bacterioplankton populations induced by a phytoplankton bloom. Science 336, 608-611.doi: 10 . 1126/science.1218344

Vorhölter, F.-J., Wiggerich, H.-G., Scheidle, H., Sidhu, V. K., Mrozek, K., Küster, H., et al. (2012). Involvement of bacterial TonB-dependent signaling in the generation of an oligogalacturonide damage-associated molecular pattern from plant cell walls exposed to Xanthomonas campestris pv. campestris pectate lyases. BMC Microbiol. 12:239.doi: 10.1186/1471-2180-12-239

Webb, B. A., Compton, K. K., del Campo, J. S. M., Taylor, D., Sobrado, P., and Scharf, B. E. (2017). Sinorhizobium meliloti chemotaxis to multiple amino acids is mediated by the chemoreceptor McpU. Mol. Plant Microbe Interact. 30, 770-777.doi: 10.1094/MPMI-04-17-0096-R

Wei, Z., Gu, Y., Friman, V.-P., Kowalchuk, G. A., Xu, Y., Shen, Q., et al. (2019). Initial soil microbiome composition and functioning predetermine future plant health. Sci. Adv. 5:eaaw0759. doi: 10.1126/sciadv. aaw0759

Williams, A., Wilkinson, A., Krehenbrink, M., Russo, D. M., Zorreguieta, A., and Downie, J. A. (2008). Glucomannan-mediated attachment of Rhizobium leguminosarum to pea root hairs is required for competitive nodule infection. J. Bacteriol. 190, 4706-4715.doi: 10.1128/JB.01694-07 
Wolkin, R. H., and Pate, J. L. (1984). Translocation of motile cells of the gliding bacterium Cytophaga johnsonae depends on a surface component that may be modified by sugars. J. Gen. Microbiol. 130, 2651-2669.doi: 10.1099/00221287130-10-2651

Wu, K., Fang, Z., Guo, R., Pan, B., Shi, W., Yuan, S., et al. (2015). Pectin enhances bio-control efficacy by inducing colonization and secretion of secondary metabolites by Bacillus amyloliquefaciens SQY 162 in the Rhizosphere of Tobacco. PLoS One 10:e0127418. doi: 10.1371/journal.pone.0127418

Xue, C., Ryan Penton, C., Shen, Z., Zhang, R., Huang, Q., Li, R., et al. (2015). Manipulating the banana rhizosphere microbiome for biological control of Panama disease. Sci. Rep. 5:11124. doi: 10.1038/srep11124

Yan, Y., Yang, J., Dou, Y., Chen, M., Ping, S., Peng, J., et al. (2008). Nitrogen fixation island and rhizosphere competence traits in the genome of root-associated Pseudomonas stutzeri A1501. Proc. Natl. Acad. Sci. U.S.A. 105, 7564-7569.doi: $10.1073 /$ pnas.0801093105
Zimbler, D. L., Arivett, B. A., Beckett, A. C., Menke, S. M., and Actis, L. A. (2013). Functional features of TonB energy transduction systems of Acinetobacter baumannii. Infect. Immun. 81, 3382-3394. doi: 10.1128/IAI.00540-13 doi: 10.1128/iai.00540-13

Conflict of Interest: The authors declare that the research was conducted in the absence of any commercial or financial relationships that could be construed as a potential conflict of interest.

Copyright (c) 2021 Kraut-Cohen, Shapiro, Dror and Cytryn. This is an open-access article distributed under the terms of the Creative Commons Attribution License (CC BY). The use, distribution or reproduction in other forums is permitted, provided the original author(s) and the copyright owner(s) are credited and that the original publication in this journal is cited, in accordance with accepted academic practice. No use, distribution or reproduction is permitted which does not comply with these terms. 